\title{
ARTE, IMAGEM E FOTOGRAFIA: UM DIÁLOGO POSSÍVEL ENTRE ROLAND BARTHES, WALTER BENJAMIN E JACQUES RANCIÈRE ${ }^{*}$
}

\author{
ART, IMAGE AND PHOTOGRAPHY: A POSSIBLE DIALOGUE \\ BETWEEN ROLAND BARTHES, WALTER BENJAMIN AND \\ JACQUES RANCIÈRE
}

DOI: http://dx.doi.org/10.15448/2178-3748.2016.1.20316

\author{
Andre Fabiano Voigt \\ Doutor em História - Universidade Federal de Santa Catarina \\ E-mail: voigtandre@hotmail.com \\ Miriam Mendonça Martins \\ Graduanda em História - Universidade Federal de Uberlândia \\ E-mail: mmm.miriam.martins@gmail.com
}

\begin{abstract}
RESUMO: O presente artigo objetiva estabelecer um diálogo entre três autores que escreveram trabalhos importantes sobre a relação da arte com as imagens e a fotografia. Enquanto os pensamentos de Roland Barthes e Walter Benjamin se assemelham, Jacques Rancière apresenta uma postura dissonante ao analisar arte, imagem e fotografia no interior do que ele chama de regime estético das artes.
\end{abstract}

PALAVRAS-CHAVE: Fotografia. Arte. Roland Barthes. Walter Benjamin. Jacques Rancière.

\begin{abstract}
This article aim to provide a dialogue between three writers who wrote important works about the relationship of the art with the images and the photography. While the thoughts of Roland Barthes and Walter Benjamin are similar, Jacques Rancière presents a dissonant position when analyses art, image and photography in the interior of what he calls aesthetic regime of arts.
\end{abstract}

KEYWORDS: Photography. Art. Roland Barthes. Walter Benjamin. Jacques Rancière.

Em A câmara clara (1980), Roland Barthes encontra-se diante de um paradoxo. Ao mesmo tempo em que afirma que é possível estabelecer um discurso universal que evidencie as características fundamentais de toda e qualquer imagem fotográfica, afirma também a contingência da fotografia e a impossibilidade de considerá-la filosoficamente. Mesmo caminhando entre esses dois extremos, o semiólogo francês procura demonstrar que a fotografia possui traços singulares que a distingue das outras imagens.

Deste modo, o que singulariza a foto é o seu referente fotográfico, ou seja, "a coisa necessariamente real que foi colocada diante da objetiva" (BARTHES, 1984, p. 115). Neste

\footnotetext{
"Artigo vinculado ao projeto História, arte, imagem: o conceito de "regime estético da arte" na obra de Jacques Rancière, aprovado pelo Edital CNPq 43/2013 e pelo Edital 01/2013 FAPEMIG.

Oficina do Historiador, Porto Alegre, EDIPUCRS, v. 9, n. 1, jan./jun. 2016,
} 
sentido, Barthes considera que a fotografia, ao contrário das outras imagens, não se distingue daquilo que representa e não se separa de seu referente. Tanto a pintura quanto o discurso podem simular a realidade por meio de representações, cuja veracidade pode ser duvidosa. De maneira oposta, a imagem fotográfica representa o que de fato existiu. A impossibilidade de negar a existência da coisa fotografada projeta sua realidade no passado. A conjunção entre realidade e passado configura o noema ${ }^{1}$ da foto. O que a imagem fotográfica representa esteve presente em algum momento e sua principal característica é o "isso-foi". Portanto o "traço inimitável da fotografia (seu noema) é que alguém viu o referente (mesmo que se trate de objetos) em carne e osso, ou ainda em pessoa" (BARTHES, 1984, p. 118).

De modo diverso, a linguagem, de acordo com Barthes, não consegue ratificar a si mesma. Seguindo esse raciocínio, o que se observa é que o autor acredita em uma hierarquia da imagem sobre a escrita, do olhar sobre a palavra. Enquanto a linguagem habita um campo ficcional incapaz de autenticar aquilo que representa, a fotografia é a própria autenticação. Logo, "ao Pouco-de-Imagem da leitura corresponde o Tudo-Imagem da Foto; não somente porque ela já é em si uma imagem, mas porque essa imagem muito especial se dá por completo" (BARTHES, 1984, p. 133).

Concomitante a isso, a fotografia, ao oferecer ao olhar a materialidade da coisa representada, torna o passado tão seguro quanto o presente, "o que se vê no papel é tão seguro quanto o que se toca" (BARTHES, 1984, p. 130). Nesse caso, o historiador deixa de ser o mediador. Na imagem fotográfica, o episódio se apresenta sem método, o que se tem é o "real no estado passado", sem a mediação da narrativa historiográfica.

Para Barthes, a História e a Fotografia, além de terem nascido no mesmo século, compartilham de um destino semelhante: conservar a lembrança das coisas que existiram. Entretanto, enquanto a História se utiliza do discurso intelectual para salvaguardar uma "memória fabricada segundo receitas positivas", a foto é um "testemunho seguro" do passado porque "é desprovida de futuro" (BARTHES, 1984, p. 134). Sob esse ponto de vista, a fotografia é entendida como algo imóvel, aquilo que ela dá a ver fornece garantia do real, por mais transitória que essa realidade possa ser. Desta maneira, Barthes declara que a fotografia

\footnotetext{
${ }^{1} \mathrm{O}$ conceito de noema, no sentido ao qual Barthes se refere, foi desenvolvido pela Fenomenologia de Edmund Husserl. Em Investigações Lógicas: Fenomenologia e a Teoria do Conhecimento (1901) e Meditações Cartesianas: Introdução à Fenomenologia (1931), o fenomenólogo alemão retoma e modifica os conceitos gregos de noesis e noema de modo a entendê-los como processos de apreensão e subjetivação das coisas pelo pensamento. Isto posto, o noema não é imanente aos objetos, pois é antes a forma como o sujeito cognoscente atribui sentido aos seres cognoscíveis.
} 
"reflui da apresentação para a retenção", porque o seu poder de autenticação se sobrepõe ao seu poder representativo.

Partindo de um princípio realista, ele acredita que a imagem fotográfica, por ser uma “emanação do real passado", é "uma magia, não uma arte” (BARTHES, 1984, p. 132). Por sua vez, encerra a fotografia a um ritual de culto e a considera como ícone intocável ao afastála das outras formas de arte. Diferentemente de uma pintura, estátua ou todos os quadros de um museu, para Barthes, a foto só cumpre sua função quando retida sobre uma mesa ou guardada dentro de um álbum. Essa assertiva se fundamenta na proclamada afirmação de imobilidade e obstrução do tempo, característica considerada comum a toda imagem fotográfica.

Com efeito, ao analisar qualquer fotografia, Barthes observa a existência de dois elementos: o studium e o punctum. A este propósito, segundo definição do autor, studium é o cenário geral da foto, ou seja, aquilo que é dado ao olhar do espectador e que pode ser imediatamente compreendido. De acordo com Barthes, "reconhecer o studium é fatalmente encontrar as intenções do fotógrafo, entrar em harmonia com elas, aprová-las, desaprová-las, mas sempre compreendê-las" (BARTHES, 1984, p. 48). Já o conceito de punctum é algo que assume várias definições ao longo do livro. Inicialmente, ele é considerado como o detalhe que punge e afeta. Posteriormente, o punctum passa a ser o esmagamento do tempo, a confirmação do noema da fotografia, ou seja, a certeza de que "isso está morto e isso vai morrer", pois, mesmo "que o sujeito já esteja morto ou não, qualquer fotografia é essa catástrofe" (BARTHES, 1984, p. 142).

Em vista disso, toda foto abriga uma interrupção, por mais que ela pareça envolvida em nosso cotidiano, ela carrega em si a marca de uma inatualidade. Para Barthes, a fotografia se apresenta mais próxima do teatro do que da pintura, precisamente porque ambos carregam a morte como signo comum. O teatro inicialmente esteve associado ao culto dos mortos: os atores ao se caracterizarem, desempenhavam o papel de um "corpo ao mesmo tempo vivo e morto". É essa mesma relação que Barthes encontra na foto, pois, "por mais viva que nos esforcemos por concebê-la", ela é "a figuração da face imóvel e pintada sob a qual vemos os mortos" (BARTHES, 1984, p. 53-54).

Portanto, o autor não apenas considera que a fotografia é uma "superfície imóvel", como também defende que por sua força de evidência é impossível aprofundá-la. A julgar por isso, a foto só oferece duas certezas: a primeira é a de que o objeto fotografado de fato existiu; a segunda é que a imagem fotográfica projeta essa existência no passado como forma de 
testemunho. Em função dessas circunstâncias, Barthes alega que a fotografia abriga uma loucura, uma alucinação, pois, de um lado o objeto "não está lá"; de outro, "ele realmente esteve". Assim, a imagem fotográfica é "falsa no nível da percepção e verdadeira no nível do tempo" (BARTHES, 1984, p. 169).

Segundo Barthes, a sociedade procura fazer com que a fotografia se torne sensata ao tentar transformá-la em arte e ao compará-la com as outras imagens, sem levar em conta suas singularidades. A imagem fotográfica, de acordo com esse raciocínio, deixa de ser um testemunho seguro do passado, visto que se afoga cotidianamente na inundação de outras imagens. Tal conjuntura desencadeia não só uma sensação de banalidade e insegurança, como também dificulta a capacidade do homem moderno de conceber sua duração. Em uma sociedade em que "só existem, só se produzem e só se consomem imagens", a fotografia perde todo e qualquer sentido (BARTHES, 1984, p. 173).

É por isso que o semiólogo francês pondera que a sociedade não é capaz de encarar o sentido agudo de algumas fotografias e, consequentemente, elas são desviadas de seu sentido político. Por vezes, diante da sua contingência, a foto só pode possuir um sentido puro à medida que assume uma máscara. Embora esse sentido possa inquietar, ele não consegue construir uma crítica social eficaz, uma vez que, segundo Barthes, a fotografia da máscara é consumida de maneira estética e não de forma política. Ao considerar que estética e política são campos opostos, o autor parte do princípio de que a imagem fotográfica, no seu sentido puro, é tão distinta que não consegue ser decodificada pelas massas. Daí a circunstância de ela não produzir um efeito político condizente com as exigências do militantismo. Por conseguinte, o autor salienta que somente um olhar treinado consegue entender o significante fotográfico e, assim, acessar o sentido puro que a máscara proporciona à imagem fotográfica:

o Notário de Sander está marcado por importância e rigidez, seu Oficial de Justiça por afirmação e brutalidade ${ }^{2}$; mas jamais um notário ou um oficial de justiça poderiam ler esses signos. Como distância, o olhar social passa aqui necessariamente pelo revezamento de uma estética fina, que a torna vã: só é crítico naqueles que já estão aptos para a crítica (BARTHES, 1984, p. 60).

\footnotetext{
2 August Sander (1876 - 1964), fotógrafo alemão, cujo principal trabalho é o ensaio Menschen des 20. Jahrhunderts (Pessoas do século 20) realizado entre 1920 e 1930. Nesse ensaio, o fotógrafo registrou diversos segmentos da sociedade da época, desde camponeses até notários e oficiais de justiça. É importante ressaltar que o próprio Sander, considerado um dos maiores fotógrafos do período entre-guerras, teve seu primeiro contato com a fotografia quando trabalhava em uma mina de carvão. Referência em: http<foto.espm.br/index.php/referencias/o-povo-alemao-do-seculo-xx-retratado-por-august-sander>. Acesso em: $14 / 02 / 2015$.
} 
Em decorrência disso, Roland Barthes enfatiza que somente as fotografias publicitárias podem ser assimiladas pelo grande público, uma vez que sua função mercadológica não exige maior sutileza e qualidade estética. A fotografia verdadeiramente revolucionária é aquela que "fala demais", sugere um sentido e leva o espectador a refletir. Para Barthes, "a fotografia é subversiva não quando aterroriza, perturba ou mesmo estigmatiza, mas quando é pensativa" (BARTHES, 1984, p. 62). No entanto, de acordo com o autor, tais fotos são desprezadas pela grande mídia por que são interpretadas como perigosas e inexploradas pelo povo, por que são demasiado penetrantes.

Em sociedades que "consomem imagens e não crenças", as fotografias pensativas só podem ser constantemente rejeitadas. Entretanto, ainda assim a fotografia pode ser sensata ou louca, "sensata se seu realismo permanece relativo, louca se esse realismo é absoluto, fazendo voltar à consciência a própria letra do tempo" (BARTHES, 1984, p. 175). Desta feita, o autor sublinha que o fotógrafo não deve querer "rivalizar com o artista", pois ele é, antes de tudo, um "agente da morte" que captura o "real no estado passado". Barthes é taxativo quando afirma que "a fotografia pode ser uma arte quando não há mais nela nenhuma loucura, quando seu noema é esquecido e consequentemente sua essência não age mais sobre mim" (BARTHES, 1984, p. 172).

De maneira semelhante, o filósofo alemão Walter Benjamin também não considera a fotografia como uma criação artística. Em seus opúsculos Pequena História da Fotografia (1931) e A obra de arte na era da sua reprodutibilidade técnica (1936), é possível identificar algumas assertivas das quais o pensamento de Roland Barthes se aproxima. A mais notória delas, é justamente o fato de ambos os autores afirmarem ostensivamente que a fotografia não é uma obra de arte. Assim sendo, enquanto Barthes julga que a foto é um testemunho do real no estado passado, Benjamin declara que ela é apenas uma reprodução encarregada pela rápida difusão e posterior popularização das verdadeiras obras artísticas. De acordo com esse raciocínio, Benjamin afirma que se existe algo que "caracteriza a relação moderna entre a arte e a fotografia, é a tensão ainda não resolvida que surgiu entre ambas quando as obras de arte começaram a ser fotografadas" (BENJAMIN, 1987, p. 104).

Desta forma, para além das reflexões que procuram qualificar a imagem fotográfica como obra de arte, o filósofo alemão assevera a necessidade de identificar a ruptura que o advento da fotografia provocou no campo artístico. A necessidade cada vez mais premente de possuir o objeto o mais próximo possível foi parcialmente sanada pela reprodutibilidade do mesmo. Entretanto, Benjamin considera que entre a reprodução e a obra de arte existe um 
abismo intransponível: ao passo que a primeira está inevitavelmente relacionada com a comercialização, a segunda está tradicionalmente vinculada à apreciação e ao valor de culto. À vista disso, enquanto para Benjamin a reprodução fotográfica é efêmera e transitória porque não consegue nunca captar a unicidade e durabilidade da imagem verdadeira, para Barthes a fotografia é contingente e efêmera por que registra pequenos momentos que se perdem na ampla temporalidade da duração.

Ademais, de acordo com Benjamin, nenhuma reprodução pode apreender o "aqui e agora da obra de arte, sua existência única, no lugar em que ela se encontra" (BENJAMIN, 1987, p. 167). Essa unicidade configura precisamente a aura, a autenticidade da produção artística. Inicialmente, tais produções - devido ao peso que o valor de culto exercia sobre elas, antes de serem reconhecidas como obras de arte - eram consideradas como instrumentos de magia.

Na fotografia, Benjamin avalia que o valor de exposição se sobrepõe ao valor de culto quando as fotos deixam de retratar o rosto humano. Para ele, "o refúgio derradeiro do valor de culto foi o culto da saudade, consagrado aos amores ausentes ou defuntos. A aura acena pela última vez na expressão fugaz de um rosto, nas antigas fotos” (BENJAMIN, 1987, p. 174). Nesse ponto, há uma profunda consonância entre a visão de Benjamin e Barthes sobre a imagem fotográfica. Um e outro concordam que "a aura das primeiras fotografias" está no fato delas terem começado como "uma arte da pessoa: de sua identidade, de seu caráter civil" (BARTHES, 1984, p. 118-119). Da mesma forma, os dois admitem que a foto é um signo de recordação e lembrança, um significante que remete ao passado e carrega em seu interior a marca da ausência e da morte. Destarte, Barthes considera que a fotografia é magia e não arte, por nela ver o valor de culto do qual fala Benjamin. Para ambos, a foto é um ícone de recordação familiar que cumpre sua função quando encerrada no interior de algum álbum ${ }^{3}$. Quando a imagem fotográfica se distancia desse universo privado, os autores consideram que ela se torna banal e mercadológica.

Diante disso, o filósofo alemão presume que a criatividade do fotógrafo é um fetiche comercial, que se acentua conforme a "crise da atual ordem social" se propaga. Para o autor,

$\mathrm{Na}$ fotografia, ser criador é uma forma de ceder à moda. Sua divisa é: “o mundo é belo". Nela se desmascara a atitude de uma fotografia capaz de realizar infinitas montagens com uma luta de conservas, mas incapaz de compreender um único dos contextos humanos em que ela aparece. Essa fotografia está mais a serviço do valor de venda de suas criações, por mais

\footnotetext{
${ }^{3}$ Isto fica muito evidente na segunda parte de A Câmara Clara, quando Barthes se dedica a falar de sua busca por uma fotografia que lhe fizesse recordar sua falecida mãe.
} 
oníricas que sejam, que a serviço do conhecimento. (BENJAMIN, 1987, p. 105-106).

Deste modo, para que a fotografia não esteja "a serviço do valor de venda", é importante que ela estabeleça uma relação estreita com a realidade da qual faz parte. Assim, tanto Benjamin quanto Barthes asseveram que ser criativo não é da alçada do fotógrafo, e sim do artista. É interessante perceber que a posição dos autores também se assemelha no que diz respeito à relação das massas com as produções culturais. Em vista disso, Benjamin afirma que determinadas artes, como a pintura, não nasceram para apreciação do grande público. Isso porque, "por mais que se tentasse confrontar a pintura com a massa do público, nas galerias e salões, esse público não podia de modo algum, na recepção das obras, organizar-se e controlar-se" (BENJAMIN, 1987, p. 188). Para o autor, a pretensão da obra de arte de se dirigir às massas representa o início de uma crise que se aprofunda ainda mais com a era da reprodutibilidade técnica. Barthes, tal como Benjamin, também subestima a capacidade de julgamento estético das massas. O semiólogo francês, como já vimos, afirma que o grande público é incapaz de captar o sentido agudo de algumas fotos, bem como, um notário ou um oficial não são competentes para distinguir os signos presentes nas fotografias de August Sander.

De acordo com Benjamin, a aura dos primórdios da fotografia cede espaço para que a câmera capture fotos cada vez mais "efêmeras e secretas". Tais imagens causam tanto impacto que "paralisam o mecanismo associativo do espectador"; por isso, é necessário que a legenda "sem a qual qualquer construção fotográfica corre o risco de permanecer vaga e aproximativa" acompanhe as fotos, de modo a "favorecer a literalização de todas as relações da vida" (BENJAMIN, 1987, p. 107).

Desta forma, enquanto Barthes afirma que a imagem fotográfica fala mais que o documento escrito, Benjamin sugere que a foto só pode ser entendida com o auxílio do texto. Os dois não conseguem pensar a fotografia sem categorizá-la, assim como não conseguem compreender a arte sem submetê-la à hierarquia do texto sobre a imagem ou vice-versa. De certo modo, para ambos os autores, a intensa produção e reprodução de imagens é algo que provoca rupturas não só na interação entre arte e público, mas também na vida do homem moderno e na sua relação com o tempo histórico. Tanto um como outro professam uma visão desencantada de um mundo em que, segundo eles, tudo parece ter se transformado em 
"consumo de imagens", onde as mais arraigadas tradições se perdem na banalidade dos novos hábitos modernos.

A esse respeito, o filósofo francês Jacques Rancière diverge substancialmente das proposições levantadas por Roland Barthes e Walter Benjamin sobre imagem, arte e fotografia. Nestas condições, no livro $O$ espectador emancipado (2008), Rancière sustenta que é necessário questionar a tese de que o excesso de imagens é a causa dos males da sociedade moderna. Contrariamente ao que se pensa, tais imagens não aparecem em profusão, pois são minuciosamente selecionadas para que não ilustrem mais do que seu próprio significado. O que há em demasia, de acordo com o autor, é a quantidade de especialistas e governantes a dizerem o que as imagens mostram e o que devemos pensar a respeito. Desse modo, vemos corpos sem nomes, "corpos que são objeto de palavra sem terem a palavra", inseridos em um sistema que "consiste em nos ensinar que não é qualquer um que é capaz de ver e falar" (RANCIÈRE, 2012 b, p. 94). Por conseguinte, facilmente se presume que o problema não está em opor palavras e imagens e julgar qual das duas é mais competente para explicar o real. A grande questão é controverter a lógica dominante que determina que as palavras devam ser utilizadas por poucos para explicar ao grande público o que as imagens representam.

É nesse sentido que Rancière entende que estética e política não se separam. Em seu livro, Políticas da escrita (1995), ele assinala que a ordem política que estrutura o corpo social está baseada em uma partilha do sensível, que determina "a distribuição dos corpos de acordo com suas atribuições e finalidades" e a circulação do sentido de acordo com "a ordem do visível e do dizível". Desta forma, a política é estética, na medida em que "é um modo de determinação do sensível", "uma forma de visibilidade e de dizibilidade do que é próprio e do que é comum" (RANCIÈRE, 1995, p. 8).

Para além das visões tradicionais da política - como a de Aristóteles - que estabeleciam o lugar de fala dos indivíduos de acordo com suas ocupações/posições sociais, em A partilha do sensível (2000), Rancière afirma que a política é, antes de tudo, uma estética primeira que permite dar visibilidade às práticas da arte. De acordo com ele, "as práticas artísticas são "maneiras de fazer" que intervêm na distribuição geral das maneiras de fazer e nas suas relações com maneiras de ser e formas de visibilidade" (RANCIÈRE, 2009 a, p. 17). Em outras palavras, os modos de pensatividade da arte se interligam às diferentes formas de conceber a organização política no interior da comunidade. Portanto, convém ressaltar que é

Oficina do Historiador, Porto Alegre, EDIPUCRS, v. 9, n. 1, jan./jun. 2016, 
em conjunto com a política que as "práticas estéticas" - ou seja, os regimes da arte - podem ser identificados.

Diante disso, Rancière distingue três regimes da arte. O primeiro deles é o regime ético das imagens, nele a arte se encontra subsumida em uma discussão imagética sobre o teor de verdade, o destino e a origem das imagens. Desse regime, deriva um segundo, o regime poético/representativo. Este, por sua vez, é intitulado poético porque classifica as artes segundo "maneiras de fazer e apreciar imitações bem feitas", e designado representativo porque é a noção de mímesis ou representação que "organiza essas maneiras de fazer, ver e julgar" (RANCIÈRE, 2009 a, p. 32). Como se pode observar, no regime representativo a autonomia da arte fica submetida a uma hierarquia que avalia as produções artísticas de acordo com os "modos de fazer" específicos a cada tipo de arte. Contrariamente aos regimes ético e representativo, está o regime estético. Esse regime "identifica a arte no singular e desobriga essa arte de toda e qualquer regra específica, de toda hierarquia de temas, gêneros e artes" (RANCIÈRE, 2009 a, p. 33, 34). Esta igualdade de todos os temas é também a igualdade de todas as pessoas, a possibilidade de qualquer um estabelecer seus próprios julgamentos sobre as obras de arte.

Isto é plausível porque, de acordo com Rancière, o grande manifesto desse regime está pautado na premissa kantiano-schilleriana de suspenção de todo e qualquer primado do entendimento sobre a sensibilidade. Friedrich Schiller em A educação estética do homem (1795), influenciado pelo pressuposto kantiano de que o julgamento estético não está submetido a qualquer determinação conceitual, rompe com a partilha política que fixava o entendimento ativo para aqueles que pensam e a sensibilidade passiva para os que realizam trabalhos manuais. No estado estético, há uma revolução na partilha do sensível. Conforme Schiller, "todos - mesmo o que é instrumento servil - são cidadãos livres que têm os mesmos direitos que o mais nobre, e o entendimento, que submete violentamente a massa dócil a seus fins, tem aqui de pedir-lhe o assentimento" (SCHILLER, 2011, p. 135). Em virtude disso, Rancière, em seu artigo A comunidade estética (2002), argumenta que a revolução estética não apenas destrói com a lógica de dominação pautada na diferença das naturezas, como também transforma a comunidade política, ao revogar "o poder da classe culta e civilizada sobre a natureza selvagem popular" (RANCIÈRE, 2011 a, p. 172).

Tendo isto em vista, no regime estético a arte está em estreita relação com a vida coletiva. Todavia, essa relação, ao contrário do que o regime representativo pressupõe, não pretende entender o "contexto histórico" como fundamento para intervir nas organizações

Oficina do Historiador, Porto Alegre, EDIPUCRS, v. 9, n. 1, jan./jun. 2016, 
sociais. Acima de tudo, o regime estético postula um dissenso entre intencionalidade do autor e receptividade coletiva; em decorrência disso, não é necessário uma "estética fina" ou um crítico apto para identificar os signos contidos em nenhuma produção artística. O mesmo sucede com os temas da arte. No regime estético, não há uma divisão que classifique o que é arte pura e o que é arte utilitária, pois independente de qualquer classificação, a arte está, antes de tudo, a serviço da vida. Desta maneira, em $O$ inconsciente estético (2001), Rancière afirma que "não existem temas nobres e temas vulgares, muito menos episódios narrativos importantes e episódios descritivos acessórios" (RANCIÈRE, 2009 b, p. 36).

É somente no interior do regime estético, que abole toda categorização hierárquica dos modos de fazer arte, que Rancière pode afirmar que a fotografia é uma produção artística. Ao contrário de Barthes e Benjamin, ele não considera a foto nem como testemunho inequívoco da realidade, nem como reprodução das "verdadeiras formas artísticas".

Em $O$ destino das imagens (2003), o filósofo francês assevera que a destruição do regime representativo na pintura, ainda no início do século XIX, fez com que a representação de pessoas comuns fosse reabilitada pela pintura de gênero em detrimento da pintura histórica. Tal acontecimento desencadeou uma reviravolta que transformou inevitavelmente o estatuto das imagens, tornando-as "não mais um duplo ou uma tradução, mas uma maneira como as próprias coisas falam e se calam" (RANCIÈRE, 2012 a, p. 22).

A partir disso, a fotografia, ao capturar o mistério e a inexpressividade dos rostos anônimos, cumpre seu mister no âmago da poética das imagens e funciona, por sua vez, como "vetor de uma identificação renovada entre a imagem como operação da arte e a imagem como produção de uma representação" (RANCIÈRE, 2012 b, p. 105).

Contudo, discursos teóricos pertencentes "menos à história da fotografia que à história da reviravolta pós-moderna” (RANCIÈRE, 2009 a, p. 48) demarcam a oposição entre arte e produção fotográfica. Sob tal perspectiva, autores como Roland Barthes veem a fotografia como a própria "emanação dos corpos", representativa de uma realidade única, desvinculada de qualquer significação exterior a si própria. De acordo com Rancière, essas análises indiciais que procuram na imagem fotográfica a verdade, o passado ou qualquer vestígio do real, acabam rompendo com a multiplicidade de significações que são atribuíveis às fotos por intermédio de leituras dissonantes. Basta ver que, a fotografia é um "jogo complexo de relações entre o visível e o invisível, o visível e a palavra, o dito e o não dito. Não é a simples reprodução daquilo que esteve diante do fotógrafo" (RANCIÈRE, 2012 b, p. 92).

Oficina do Historiador, Porto Alegre, EDIPUCRS, v. 9, n. 1, jan./jun. 2016, 
Rancière se atenta para o fato de que Barthes reduz o ato fotográfico e o olhar para a foto a um processo único quando opõe a pensatividade do punctum ao aspecto informativo do studium. Ao fazer isso, o semiólogo francês, além de ignorar a intenção do fotógrafo e igualar a percepção óptica à sensação tátil, ainda reduz uma complexa produção técnica a um simples processo químico. De acordo com Rancière, a loucura que Barthes diz que a foto abriga é, na verdade, a submissão do olhar a uma interpretação que só atribui validade à fotografia enquanto ela permite rememorar o passado. Eis, pois, que "contrapor imagem e arte não é apenas negar o caráter da imagem como objeto de fabricação; é, em última análise, negar seu caráter de coisa vista” (RANCIÈRE, 2012 b. p. 106).

Concomitante a isso, a teoria do noema (isso-foi) e do punctum (isso vai morrer) muito além de destacar a especificidade da fotografia, caracteriza-a como um produto mágico que assegura a presença dos ancestrais entre os vivos. Rancière associa essa interpretação da foto à perspectiva que o regime ético possui sobre as imagens. Nesse regime, a legitimidade de qualquer imagem provém de sua capacidade de representar, da forma mais verossímil possível, a fisionomia humana. Como vimos, não apenas Barthes, mas também Benjamin, considera que o valor de culto da fotografia está na possibilidade de rememorar os "amores ausentes ou defuntos". Entretanto, ambos os autores escrevem "num mundo e num século em que não só as obras de arte, mas também as imagens em geral, são apreciadas por si mesmas, e não como almas de ancestrais" (RANCIÈRE, 2012 b, p. 109). Sendo assim, a fotografia não carrega nem o signo da morte, nem a certeza de um real no estado passado e menos ainda a lembrança de pessoas que morreram, ela é em si, portanto, uma indeterminação.

Em virtude disto, Rancière afirma que a imagem fotográfica não é pensativa da maneira como Barthes propõe. De acordo com o filósofo francês, a imagem pensativa não pode ser subversiva, pois “encerra pensamento não pensado", ou seja, ela não sugere nenhum sentido a priori e nem direciona o espectador a uma determinada reflexão. A imagem pensativa é, portanto, "pensamento não atribuível à intenção de quem a cria e que produz efeito sobre quem a vê sem que este a ligue a um objeto determinado" (RANCIÈRE, 2012 b, p. 103). A fotografia pensativa é marcada pela indeterminação, não só porque abriga vários modos de representação e permite diferentes tipos de interpretação, mas também porque abriga dois regimes de expressão (linguagem narrativa e linguagem visual) sem que um se sobreponha ao outro. Desta feita, a pensatividade da imagem "não é a aura ou o punctum do aparecimento único", mas sim, "essa relação entre duas operações que põe fora de si mesmos a forma pura demais ou o acontecimento carregado demais de realidade" (RANCIÈRE, 2012

Oficina do Historiador, Porto Alegre, EDIPUCRS, v. 9, n. 1, jan./jun. 2016, 
b, p. 116/122). Note-se, assim, que Rancière, ao ressignificar a noção de "fotografia pensativa" proposta por Barthes, implode com toda a episteme elaborada para legitimar o enunciado de que a imagem fotográfica é um testemunho efetivo do passado.

Mediante o exposto, Jacques Rancière pondera que no regime estético, não existe um conceito que demarque o que é comum a todas as formas artísticas, assim como não existe um "próprio" que delimite o que é singular a cada tipo de arte. Nessa situação, qualquer matéria espalhada em uma superfície pode ser considerada como arte, desde que um olhar a veja como tal. É antes no intercâmbio entre os diversos "modos de fazer" e nos diferentes efeitos da produção que o fotógrafo se torna artista e o artista se aproxima do revolucionário, “inventor da vida nova” (RANCIÈRE, 2009 a, p. 23). Desta forma, nem a imagem necessita de um texto explicativo para ser entendida, nem a escrita precisa de ser autenticada para ser considerada como válida. No regime estético, signos e palavras se concatenam não mais em função de uma submissão, mas sim de maneira a garantir "a autonomia da arte das palavras, da arte das formas visíveis e de todas as outras artes" (RANCIÈRE, 2012 a, p. 49).

É seguindo essa mesma lógica que a divisão, característica do regime representativo, entre arte para apreciação e arte para comercialização, cai por terra. Assim, no regime estético “caminham juntas a pureza da arte e a associação de suas formas com as formas da vida" já que "o mesmo artista faz quadros abstratos e cartazes utilitários, e, num e noutro caso, trabalha igualmente na construção de novas formas de vida" (RANCIÈRE, 2012 a, p. 117 118). Tendo isso em vista, fotografia, cinema, desenho, se dissolvem e intercambiam seus significados produzindo novas maneiras de pensar a arte. Como afirma o filósofo francês, "essas combinações criam formas de pensatividade da imagem que refutam a oposição entre studium e o punctum, entre a operatividade da arte e a imediatez da imagem" (RANCIÉRE, 2012 b, p. 119).

Assim, a fotografia rompe com a lógica mimética não só ao suspender a relação entre realidade, verdade e passado, mas também ao retratar coisas e pessoas que simultaneamente estão impregnadas de suas histórias e se apresentam aos espectadores como seres incapazes de estimular qualquer narrativa que tente desvendar os signos por trás de seus corpos. Como certifica Rancière,

A fotografia não se tornou uma arte porque aciona um dispositivo opondo a marca do corpo à sua cópia. Ela tornou-se arte explorando uma dupla poética da imagem, fazendo de suas imagens, simultânea ou separadamente, duas coisas: os testemunhos legíveis de uma história escrita nos rostos ou nos

Oficina do Historiador, Porto Alegre, EDIPUCRS, v. 9, n. 1, jan./jun. 2016, 
objetos e puros blocos de visibilidade, impermeáveis a toda narrativização, a qualquer travessia do sentido (RANCIÈRE, 2012 a, p. 20).

É esta impossibilidade de elaborar uma narrativa que atribua sentidos inequívocos, que faz com que a indeterminação estética seja o principal atributo da fotografia na arte contemporânea. A imagem fotográfica, em conformidade com o que Rancière afiança, impõe presenças brutas de "seres sobre os quais não sabemos o que os levou a posar diante de um artista, nem o que pretendem mostrar e expressar diante da objetiva" (RANCIÈRE, 2012 b, p. 110-111). Deste modo, tais imagens são como palavras mudas que dão a ver os sinais escritos nos corpos como uma linguagem visível pronta a ser decifrada, mas ao mesmo tempo encerram um "mutismo obstinado" que faz "da incapacidade de transferência adequada de significações sua própria potência" (RANCIÈRE, 2012 a, p. 22).

Como vimos anteriormente, Benjamin associa o surgimento da reprodução fotográfica à mudança de paradigmas, que fez com que o grande público estabelecesse novas relações com as produções artísticas. Entretanto, antes mesmo do advento das primeiras fotografias, o homem comum já estava sendo representado pelas pinturas de gênero. Desta maneira, Rancière declara que foi inicialmente pela revolução estética que os excluídos na partilha do sensível tiveram seu primeiro contato com as obras de arte. ${ }^{4}$ Nas palavras do próprio autor, "a revolução técnica vem depois da revolução estética, mas a revolução estética é antes de tudo a glória do qualquer um" (RANCIÈRE, 2009 a, p. 48).

Neste sentido, ao contrário do que Benjamin supõe, a arte não entrou em crise quando passou a ser acessível ao grande público, o que entrou em crise foi o regime representativo, que determinava - de acordo com a posição social - o tipo de arte que cada indivíduo poderia ter acesso (comédia para os pobres, tragédia para os nobres). Diante disso, a reprodução de obras de arte, antes de romper com a aura ou com a autenticidade do original, cumpre uma função mais importante ao permitir que qualquer indivíduo tenha acesso a obras que ou estão concentradas em grandes centros, ou estão monopolizadas por grandes colecionadores. Desse modo, contrariamente ao que Barthes cogita, a imagem verdadeiramente revolucionária não é aquela que sugere um sentido e faz o espectador refletir, mas sim aquela que pode ser "vista no espaço neutro do museu ou mesmo nas reproduções das enciclopédias por preço módico" (RANCIÈRE, 2012 b, p. 62).

\footnotetext{
${ }^{4}$ É importante ressaltar que essa revolução, ao colocar os indivíduos anônimos no centro das novas produções, influenciou também a mudança de cânones no interior do discurso historiográfico. Neste caso, se existe algo que aproxima a História da Fotografia é o fato de que ambas "se inscrevem na mesma lógica da revolução estética" (RANCIÈRE, 2009 a, p. 49).
} 
Acima de tudo, ao manipular um modo de visibilidade compartilhado por todos, a imagem cria um senso comunitário. A grande questão que Rancière evidencia, a partir do conceito de regime estético da arte, é a necessidade de se construir novas formas de sensível partilhado, novas significações e novos dispositivos espaçotemporais que permitam a elaboração de outras formas de senso comunitário. Desta maneira, "as imagens da arte não fornecem armas de combate", elas só contribuem "para desenhar configurações novas do visível, do dizível e do pensável" quando "não são antecipadas por seus sentidos e não antecipam seus efeitos" (RANCIÈRE, 2012 b, p. 99-102). A fotografia configura-se como arte porque carrega em si uma indeterminação que não só cria outros modos de pensatividade das imagens, como também impossibilita a antecipação de qualquer efeito pré-estabelecido pelo fotógrafo. As observações levantadas por Rancière permitem-nos pensar a relação entre arte, imagem e fotografia não mais no interior de regimes hierárquicos que submetiam a sensibilidade ao entendimento e separavam a estética da política, mas sim, a partir do regime estético das artes, que por meio de uma reconfiguração da comunidade política, estabelece a igualdade dos ajuizamentos estéticos.

\section{REFERÊNCIAS BIBLIOGRÁFICAS}

BARTHES, Roland. A câmara clara: nota sobre a fotografia. Rio de Janeiro: Nova Fronteira, 1984.

BENJAMIN, Walter. A obra de arte na era da sua reprodutibilidade técnica. In: Obras escolhidas. Vol. 1. Magia e técnica, arte e política. Ensaios sobre literatura e história da cultura. São Paulo: Brasiliense, 1987, p. 165-196.

Pequena História da Fotografia. In: Obras escolhidas. Vol. 1. Magia e técnica, arte e política. Ensaios sobre literatura e história da cultura. São Paulo: Brasiliense, 1987, p. 91-107.

KANT, Immanuel. Crítica da Faculdade do Juízo. Rio de Janeiro: Forense Universitária, 2012.

RANCIÈRE, Jacques. A comunidade estética. Revista Poiésis, Niterói, n. 17, p. 169- 187, jul. 2011a. Disponível em: <http://www.poiesis.uff.br/PDF/poiesis17/Poiesis_17_ TRAD_Comunidade.pdf $>$. Acesso em: 21 jan. 2015.

. A partilha do sensível. São Paulo: EXO experimental org.; Ed. 34, 2009a. O destino das imagens. Rio de Janeiro: Contraponto, 2012a.

Oficina do Historiador, Porto Alegre, EDIPUCRS, v. 9, n. 1, jan./jun. 2016, 
O inconsciente estético. São Paulo: Ed. 34, 2009b.

. O espectador emancipado. São Paulo: Editora WMF Martins Fontes, 2012 b.

Políticas da escrita. Rio de Janeiro: Ed. 34, 1995.

SCHILLER, Friedrich. A educação estética do homem. São Paulo: Iluminuras, 2011.

ARTIGO ENVIADO EM: 03.03.2016

ACEITO PARA PUBLICAÇÃO EM: 23.05.2016 